\title{
EXPERIÊNCIAS COM O ENSINO MÉDIO INTEGRADO DO IFMT: A GINÁSTICA LABORAL COMO CONTEÚDO DA EDUCAÇÃo Física
}

\author{
EXPERIENCES WITH IFMT INTEGRATED HIGH SCHOOL: LABOR \\ GYMNASTICS AS CONTENT OF PHYSICAL EDUCATION
}

DOI: http://dx.doi.org/10.23926/RPD.2526-2149.2020.v5.n1.p81-99.id629

\section{Larissa Beraldo \\ Kawashima \\ Doutora em Educação \\ (UFMT) \\ Professor no Instituto \\ Federal de Mato Grosso \\ (IFMT/Cuiabá Octayde). \\ larissa.kawashima@cba.ifmt. edu.br}

\section{Ana Paula \\ Vasconcelos da Silva \\ Mestre em Educação Física \\ (UFMT) \\ Professor no Instituto \\ Federal de Mato Grosso \\ (IFMT/Barra do Garças). \\ ana.silva@bag.ifmt.edu.br}

\section{Evando Carlos \\ Moreira}

Doutor em Educação Física

(UNICAMP)

Professor na Universidade

Federal de Mato Grosso

(UFMT)

ecmmoreira@uol.com.br
Resumo: $O$ presente artigo tem por objetivo apresentar duas experiências com o conteúdo de ginástica, mais especificamente de ginástica laboral, em turmas de cursos técnicos integrados ao Ensino Médio do IFMT. O artigo se caracteriza como um relato de experiência, de natureza qualitativa-descritiva, tendo como lócus das experiências as aulas de Educação Física do curso técnico em administração do campus Barra do Garças e do curso técnico em agropecuária do campus São Vicente, sendo os sujeitos os alunos matriculados respectivamente nos $2^{\circ}$ anos e $3^{\circ}$ anos de cada curso. Em ambas experiências, seguiu-se uma sequência pedagógica que permitiu aos alunos apreender conceitos, realizar diagnósticos, desenvolver atividades práticas e avaliar continuamente as etapas concluídas. Os alunos se sentiram valorizados e motivados com as sequências pedagógicas, avaliações e metodologias adotadas, além de serem instigados a aprender para ensinar, formando sujeitos críticos e autônomos, capazes de agir no e sobre o mundo.

Palavras-chave: Ginástica laboral; Prática pedagógica; Educação física.

\begin{abstract}
This article aims to present two experiences with the content of gymnastics, specifically labor gymnastics, in groups of technical courses integrated with IFMT High School. The article is characterized as an experience report, of qualitative and descriptive nature, having as locus of experiences the Physical Education classes of the technical course in administration of the Barra do Garças campus and the technical course in agriculture of the São Vicente campus, being the subjects students enrolled respectively in the 2nd and 3rd years of each course. In both experiments, a pedagogical sequence followed which allowed students to grasp concepts, perform diagnostics, develop practical activities and continually evaluate the completed stages. Students felt valued and motivated by the pedagogical sequences, assessments and methodologies adopted, and were encouraged to learn to teach, forming critical and autonomous subjects, able to act in and about the world.
\end{abstract}

Keywords: labor gymnastics; pedagogical practice; physical education. 


\section{INTRODUÇÃO}

A Educação Física é considerada componente curricular obrigatório na Educação Básica e deve ser integrada à proposta pedagógica da escola (BRASIL, 1996), porém, a lei não é garantia de reconhecimento perante a sociedade de seu papel fundamental na formação integral dos alunos. Neste sentido, a legitimidade da Educação Física escolar está associada ao reconhecimento e equiparação desta com os demais componentes curriculares presentes no currículo escolar. Esse reconhecimento deve acontecer mediante a efetivação de uma prática docente contextualizada, em que toda a comunidade escolar, respeite e valorize os conhecimentos tratados pela Educação Física como parte de um todo, integrados aos objetivos da escola.

Pensar numa efetiva legitimação da Educação Física na escola/Ensino Médio significa que não devemos abandonar a condição de estudante (FENSTERSEIFER; GONZÁLEZ, 2013, p. 40). No entanto, a sociedade só se sensibilizará da condição da Educação Física ser um componente curricular como os demais se ela reconhecer nos professores, esse conhecimento, ou seja, “[...] o diploma garante legalidade, mas não podemos confundir com legitimidade social. Esta é resultado do nosso trabalho, e este está sempre a exigir novos conhecimentos”.

Para González e Fensterseifer (2009), com o movimento renovador na Educação Física escolar, novos questionamentos que não faziam parte de tradição da área começaram a demarcar as teorias pedagógicas, tais como o porquê da Educação Física compor o currículo da escola, quais são seus objetivos, conteúdos e como são sistematizados ao longo da Educação Básica, como esses conteúdos devem ser ensinados ou como avaliar seu ensino.

[...] Segundo nossa percepção, a inclusão dessas preocupações na área imprimiu uma mudança de tal magnitude que é possível comparar esse fenômeno a um ponto de inflexão na qual a trajetória da EF faz uma quebra definitiva com sua tradição legitimadora. É dizer que aquilo que nos sustentava como área no plano da legitimidade autoatribuída ruiu, e não temos como voltar atrás, como esquecer essa inflexão.

Assim, essa ruptura com a tradição, do que podemos denominar de o "exercitar para", colocou à EF (é bom lembrar: a seus protagonistas) a necessidade de reinventar o seu espaço na escola, agora com o caráter de uma disciplina escolar. EF na forma de um componente curricular, responsável por um conhecimento específico (inclusive conceitual), subordinado a funções sociais de uma escola republicana, comprometida com a necessidade que as novas gerações têm de conhecimentos capazes de potencializá-los para enfrentar os desafios do mundo contemporâneo (GONZÁLEZ; FENSTERSEIFER, 2009, p. 11-12).

Isto posto, identificamos uma dificuldade quando os alunos chegam ao ensino médio no IFMT, trazendo uma bagagem de conhecimentos inconsistentes em Educação Física, caracterizando-se por uma confusão do componente curricular com a recreação, o lazer e os 
esportes. Ainda, a Educação Física tendo seus conteúdos baseados nas manifestações da cultura corporal de movimento, abordando as brincadeiras e os jogos, esportes, ginásticas, danças, lutas e as práticas corporais de aventura, deve oferecer diversas possibilidades de experimentação aos alunos, aprofundando seus conhecimentos sobre as potencialidades e os limites do corpo (BRASIL, 2017).

É preciso "compreender que a ginástica na escola não pode ser somente ações motoras explicadas por si mesmas, o fazer por fazer, mas sim um processo cultural construído com base em contextos sociais, políticos e históricos" (CARVALHO; DITOMASO, 2017, p. 408).

A ergonomia se relaciona com a melhoria da interação entre os seres humanos e elementos ou sistemas, de modo a adaptá-los às características e variabilidade do ser humano. É função da ergonomia contribuir para tornar locais de trabalho, produtos e sistemas compatíveis com as necessidades do homem (ABRAHÃO; SZNELWAR; SILVINO, 2009).

A ginástica laboral é um tipo de ginástica desenvolvida no ambiente de trabalho que tem por objetivo desenvolver entre os funcionários de uma organização uma melhor qualidade de vida no trabalho, evitar lesões musculares no ambiente laboral, preparar o corpo para a jornada de trabalho promovendo a interação entre os pares.

\section{REFERENCIAL TEÓRICO}

A fragmentação de conteúdos e repetição de aulas no Ensino Médio é um entrave que se agrava desde o ensino fundamental, principalmente quanto às modalidades esportivas coletivas tradicionais (voleibol, basquetebol, handebol e futebol). Esse problema é relatado por vários pesquisadores da Educação Física escolar, como Moreira, Pereira e Lopes (2009), Darido e Rangel (2005), Correia (2011), dentre outros.

Nos Institutos Federais essa realidade não é diferente, tendo como tendência pedagógica principal a prática esportiva predominante, como descreve Souza Filho (2014, p. 60):

O perfil construído ao longo da existência dos Institutos revela a tendência esportiva sem contextualização crítica com a própria história, com os valores culturais, políticos, econômicos e educacionais que permeiam o esporte como construção cultural humana e como conteúdo da Educação Física.

No IFMT, este contexto é também relatado por Almeida e colaboradores (2013), na realidade da Educação Física em três campi, sendo que no campus mais antigo e tradicional do estado, as aulas são distribuídas por modalidades, sendo elas voleibol, natação, futsal, basquetebol, handebol, ginástica e musculação, e que os alunos escolhem a modalidade, 
podendo migrar para outras durante os bimestres. Porém, mesmo com essa possibilidade de escolher modalidades diferentes e diversificar suas experiências, a maioria dos alunos escolhe a mesma modalidade nos três anos do Ensino Médio.

\begin{abstract}
Além disso, a metodologia de ensino está a critério do professor, o que o deixa livre para organizar suas aulas, não seguindo necessariamente as diretrizes e os princípios do esporte educacional propostos na ementa, na qual consta a proposta de "desenvolvimento integral do homem como ser autônomo, democrático e participante" (BITTAR, 1996), sendo facultativo ao professor decidir pela iniciação esportiva, pelo aprimoramento dos fundamentos técnicos e táticos ou pelo treinamento esportivo, práticas tradicionais neste Campus de longa trajetória (ALMEIDA et al., 2013, p. 45-46).
\end{abstract}

Neste sentido, escolher uma modalidade e/ou conteúdo não significa, necessariamente, que o professor está valorizando o conhecimento prévio do aluno e dando autonomia para que participe das decisões referentes ao currículo, mas sim está privando-o de ter acesso a diversidade de conteúdos disponíveis da cultura de movimento. Este fato, entre outros, resulta no desinteresse dos alunos pelas aulas de Educação Física no Ensino Médio e na desvalorização como componente curricular. Sua associação a um "momento de lazer" ou "de não fazer nada" é noção comum aos estudantes do ensino do médio, pois muitos não tiveram experiências significativas que pudessem mudar sua visão sobre as aulas de Educação Física.

Outro fator que contribui para a esportivização das aulas de Educação Física nos Institutos Federais são os “Jogos dos Institutos Federais” (JIFs) que abrangem todas as unidades no Brasil, a partir de etapas estaduais, regionais e nacional, captando muitos recursos e investimentos para o esporte na rede federal e, consequentemente, dando visibilidade aos professores de Educação Física. Parece ser uma forma de legitimar a Educação Física, porém de forma atravancada, já que muitos professores acabam transformando suas aulas no Ensino Médio em treinamento esportivo, valorizando apenas àqueles com mais habilidade e predisposição para se tornar um atleta.

Vago (2009, p. 38, grifo do autor) afirma

[...] penso que uma prática pedagógica de Educação Física que não contemple o esporte é empobrecedora. Mas, em sentido inverso, considero que um projeto de Educação Física que só contemple o esporte é igualmente empobrecedor da formação cultural que ela pode oferecer a crianças, jovens e adultos.

Observa-se que a crítica não é ao esporte e nem sua negação enquanto conteúdo das aulas de Educação Física, mas sim à sua supervalorização e exclusividade atribuída por alguns professores, como se fosse a única possibilidade existente (MOREIRA; PEREIRA; LOPES, 2009; NISTA-PICCOLO; MOREIRA, 2012). Do mesmo modo, a preferência do professor por um único tipo de conteúdo pode levar, além da exclusão, o abandono das aulas pelos alunos 
(RANGEL, 2009). Fica a pergunta: será que o professor deve ensinar o que os alunos querem ou o que ele prefere ensinar? Ou deve ensinar o que os alunos precisam aprender?

Sendo assim, o presente artigo tem por objetivo apresentar duas experiências com o conteúdo de ginástica, mais especificamente de ginástica laboral, em turmas de cursos técnicos integrados ao Ensino Médio do Instituto Federal de Educação, Ciência e Tecnologia de Mato Grosso, IFMT - campus Barra do Garças e campus São Vicente.

\section{Metodologia}

Este artigo se configura como um relato de experiências por apresentar as sequências pedagógicas elaboradas e executadas em dois campi do IFMT, proporcionando práticas corporais diversificadas aos alunos do Ensino Médio, trazendo sentido para as aulas e conteúdos aprendidos através de uma relação desses conhecimentos com a vida cotidiana.

Assim como Nogueira, Farias e Maldonado (2017, p. 22), relatos de nossa prática dão voz a outros educadores, nos fazendo refletir a partir da organização das ações práticas dos professores. Para os autores, "as reflexões, inseguranças e frustrações se tornam mais esperançosas quando compartilhadas com os nossos pares".

As experiências se configuram como qualitativa-descritiva, pois segundo Lüdke e André (1986) supõem o contato direto e prolongado do pesquisador com o ambiente e a situação que está sendo investigada, via de regra, através do trabalho intensivo de campo.

O lócus da experiência foram as aulas de Educação Física do curso técnico em administração do campus Barra do Garças e do curso técnico em agropecuária do campus São Vicente, sendo os sujeitos os alunos matriculados respectivamente nos $2^{\circ}$ anos (uma turma de 29 alunos) e $3^{\circ}$ anos (duas turmas, totalizando 56 alunos) de cada campi.

A apresentação dos dados seguirá os caminhos percorridos na sequência pedagógica construída e executada. É importante salientar que neste estudo a forma descritiva relatada pelos alunos nas atividades avaliativas manteve a sua originalidade, justificando assim, os erros ortográficos encontrados.

Para fins de levantamento de dados e processos avaliativos nos campi de São Vicente e Barra do Garças foram utilizadas rodas de conversa, o que segundo Mello e Cruz (2014), se caracteriza como uma rica ferramenta utilizada como prática metodológica, pois além de abrir espaços de interação possibilita a compreensão da construção de uma dada realidade por um grupo de pessoas. 
As análises de dados basearam-se na análise descritiva apresentada por Soriano (2004), com a expectativa de que resultados análogos pudessem ser encontrados nos dois campi, devido à semelhança da organização, sequência de conteúdos e prática pedagógica das professoras dos dois campi.

\section{Resultados}

As experiências serão apresentadas em duas partes, sendo a primeira o relato sobre as aulas no campus de Barra de Garças, seguidos pela descrição das aulas no campus São Vicente. Primeiramente serão apresentadas as descrições das sequências das aulas ministradas, seguidas por dados referentes às avaliações dos alunos sobre as mesmas.

\subsection{A EXPERIÊNCIA NO CAMPUS BARRA DO GARÇAS}

A experiência aqui compartilhada trata de uma sequência pedagógica executada no desenvolvimento do conteúdo de ginástica, focado mais especificamente na ginástica laboral. Para este trabalho, foram utilizadas 8 aulas de 50 minutos cada, realizadas no primeiro bimestre do ano letivo de 2019 dentro da disciplina de Educação Física no IFMT campus Barra do Garças, com a turma de $2^{\circ}$ ano do Ensino Médio Integrado ao curso técnico em administração.

A Ginástica Laboral contempla os conteúdos do $2^{\circ}$ ano do curso técnico em administração do IFMT campus Barra do Garças. A sequência pedagógica trabalhada na turma se desenhou da seguinte maneira: A origem da Ginástica; Ginástica competitiva e não competitiva; Ginástica Laboral e conceitos; tipos da Ginástica Laboral e suas aplicações no dia a dia de uma empresa.

As aulas foram desenvolvidas inicialmente no sentido de proporcionar aos alunos embasamento teórico sobre a ginástica e a ginástica laboral, trazendo conceitos, seus diferentes tipos, benefícios e sugestões de como desenvolvê-la numa empresa. Para tanto, o desenvolvimento de tal conteúdo teve por objetivos conhecer os principais conceitos da ginástica e da ginástica laboral, identificar os seus diferentes tipos, entender os benefícios da ginástica laboral tanto para funcionários quanto para empresários e compreender a aplicabilidade da ginástica laboral no trabalho.

Para este trabalho, foram descritas 8 aulas, especificamente distribuídas em 4 dias, o primeiro destinado à explicação conceitual do conteúdo, o segundo dia destinado ao debate, troca, pesquisa e interação mediados em grupo pelos alunos, o terceiro utilizado para execução da prática da ginástica laboral nos setores e o quarto dia foi destinado à avaliação as atividades, sendo cada dia composto por duas aulas. 
Na primeira aula expliquei de maneira expositiva sobre a origem da ginástica e seus diferentes tipos separados em modalidade competitiva e não competitiva, expliquei ainda o que representava cada uma, até chegar na ginástica laboral, objetivo principal das aulas seguintes.

Sobre a ginástica laboral, elaboramos slides que ilustraram funcionários de empresas de diferentes setores e em diversas situações no trabalho, alguns com más posturas, outros levantando pesos de maneira inadequada, realizando movimentos repetitivos sem intervalo e dentre as imagens comentamos a relação interpessoal daqueles funcionários. Esta introdução ao tema foi importante para que os alunos refletissem sobre a importância e os benefícios da ginástica laboral em empresas. Procurei trazer para realidade dos futuros técnicos em administração, o dia a dia de funcionários em situações de trabalho, alertando-os sobre o quanto pode ser positivo preocupar-se com a qualidade de vida no trabalho, buscando profissionais capacitados para executar esse tipo de atividades nas empresas. Após essa introdução de imagens ilustrativas foram apresentados os conceitos de ginástica laboral e suas classificações quanto a sua finalidade: preparatória, compensatória e de relaxamento.

Para Darido e Rangel (2005), os conteúdos de ensino devem ser propostos segundo três dimensões, correspondentes ao "saber fazer" (procedimentais), aos "fatos e conceitos" (conceituais) e as "atitudes, valores e normas" (atitudinais). Dessa forma, a apresentação dos conceitos sobre a Ginástica Laboral é importante para que os alunos compreendam sobre as práticas corporais que serão realizadas posteriormente.

$\mathrm{Na}$ aula seguinte, os alunos foram divididos em grupo para realização de pesquisas e debates sobre o tema. Foi proposto que cada grupo, além de produzir um artigo sobre o tema, desenvolvesse um pequeno programa prático de ginástica laboral para que fossem desenvolvidos nos diferentes setores do IFMT campus Barra do Garças. No total, formaram-se 6 grupos, sendo cada grupo responsável por realizar seu programa prático de ginástica laboral em algum setor do campus, os setores foram os seguinte: a) secretaria; b) DAP (setor administrativo)/RH; c) Sala dos Professores; d) Patrimônio/almoxarifado; e) DEN (departamento de ensino); f) Coordenações.

Após discussão teórica e compartilhada sobre o tema, os alunos montaram, em grupo na quadra, sequências de alongamentos e exercícios que pudessem ser utilizados em seus programas práticos de ginástica laboral. Os alunos foram orientados ainda a pesquisarem e pensarem em alguma atividade interativa com o propósito de, além de preparar o corpo para as atividades do trabalho, estimular uma melhor interação, diversão e ludicidade entre os 
participantes. Durante esta aula, passamos nos grupos para avaliar, orientar e ajudar a construção das atividades.

Moreira, Pereira e Lopes (2009, p. 189) afirmam que o professor pode atribuir funções para os alunos, como pesquisar sobre as atividades e o conteúdo proposto, "desde movimentos característicos até a sua origem e execução, conseguindo atingir os aspectos conceituais, procedimentais e atitudinais", incentivando-os à pesquisa, que assume um papel muito importante nesse processo.

Em seguida, cada grupo apresentou o que havia planejado para desenvolver nos setores com os quais se responsabilizaram. Este momento foi importante, tendo em vista que proporcionou uma enriquecedora troca de experiências entre os alunos. Ao final de cada apresentação, os alunos teceram comentários e sugestões que os faziam repensar e construir suas práticas. Este momento teve por objetivo verificar se os alunos assimilaram os conceitos do tema proposto e se conseguiriam colocar em prática tais conhecimentos ao elaborar a prática de ginástica laboral, considerando as necessidades e particularidade de cada setor do campus. Dessa forma, contribuímos nas discussões e construções das atividades fazendo-os refletir, criar e recriar.

$\mathrm{Na}$ semana seguinte, os alunos desenvolveram o trabalho por setores, enquanto um grupo se apresentava e desenvolvia a ginástica laboral, os outros os observavam. Os alunos foram orientados quanto à abordagem aos servidores, execução, desenvolvimento das atividades e utilização de materiais/mídias. Ao chegar nos setores eles deviam se apresentar e apresentar o trabalho a ser realizado, explicando brevemente a importância da ginástica laboral e seus benefícios, para em seguida, convidá-los e convencê-los a utilizar alguns minutos de seu trabalho para a prática proposta.

Os alunos foram avaliados durante todo o processo de criação e estudo do tema, apresentação e abordagem nos setores, execução prática das atividades de ginástica laboral, utilização de materiais e confecção de trabalho escrito. Ao final da execução prática do trabalho, os alunos agradeceram a todos pela participação e reforçaram a importância daquele tipo de atividade, orientando-os para os benefícios de uma pausa nas atividades laborais para a prática de movimentos simples de alongamento, aquecimento e relaxamento muscular e articular. Além de aprenderem o conteúdo, os alunos e servidores puderam vivenciar um pouco de como se desenvolvem tais atividades no ambiente de trabalho.

Ao final do bimestre, realizamos uma roda de conversa na sala de aula com o intuito de dar voz aos alunos no sentido de entender melhor como foi para eles participar ativamente da 
metodologia adotada para abordagem do tema. Ainda analisamos como se deu o processo de apreensão do conteúdo e o que mais puderam assimilar e observar.

Aluna 1: Então, eu achei produtivo porque até mesmo ficou melhor pra gente aprender na prática a gente tentar ensinar o que a gente aprendeu pra outras pessoas, mostrar que isso faz bem pra elas e elas deram o feedback pra gente que gostaram, que queriam que tivesse mais vezes isso. (sic.).

Aluno 1: Ah, eu achei que foi bem produtivo, foi melhor que uma aula teórica em que só o professor está ali na frente explicando, nesse tipo de aula a gente começa a interagir também como se a gente fosse o professor, como se a gente tivesse ensinando, que até então eu mesmo não sabia da existência desse tipo de ginástica, ginástica laboral e acabei aprendendo muito também que a gente pode fazer esse tipo de coisa dentro de sala de aula para que não fique uma coisa muito monótona da figura só do professor ali explicando, e as vezes acaba ficando meio chata mas com atividades práticas assim fica bem legal. (sic.).

Aluna 2: Através da atividade pudemos perceber também várias coisas que fizemos de certo pra tá ajudando eles melhorar o dia, é... os dias deles que no caso seria automático ali, a mesma coisa sempre, fazendo com que eles tenha mais vontade de tá trabalhando pelo fato de ter exercitado antes, de ter feito alguns relaxamentos, algum tempo parado assim pra melhorar tanto seu interior quanto seu exterior facilitando também a gente pra tá aprendendo melhor aquilo que nós conseguimos ter, é... como posso dizer? ter.. aprimorar, poder aprimorar o que aprendemos mesmo através da senhora. (sic.).

Num certo momento da discussão perguntamos se todos conheciam ou já tinham ouvido falar na ginástica laboral, foi quando para nossa surpresa, apenas dois alunos sinalizaram que sim, mas que não sabiam ao certo a sua importância, conceitos e diferentes tipos e que hoje conhecem não só os conceitos como são capazes de compreender a importância da ginástica laboral dentro de uma empresa. Conversamos sobre a relevância do conhecimento relacionado ao curso técnico que optaram (Administração) e o quanto a Educação Física contribui neste sentido, sendo ela a disciplina mais apropriada no assunto dentro do projeto pedagógico do curso. Os alunos avaliaram que aprenderam melhor o conteúdo participando desta metodologia na qual foram sujeitos ativos do processo de ensino aprendizagem comparado a uma aula expositiva, por exemplo.

Aluna 3: e às vezes também a gente faz a atividade laboral mesmo não sabendo o que é a gente faz despercebido por exemplo, eu lá em casa quando vou estudar pra prova ou alguma coisa do tipo eu fico toda me contorcendo lá e tipo antes de eu saber o que era atividade laboral e tudo mais eu achava que era algo meu sabe pessoal, e tipo, na verdade aqui na escola eu fiquei sabendo o real significado dela e que não é só ficar me desdobrando o corpo. (sic.).

Aluna 4: Eu acho que tipo assim, pode ocorrer de por exemplo, eles sentirem falta daquilo, igual a nossa parte era a secretaria, elas ficam ali o tempo todo, pode ser que elas sintam dor nas costas, dor de alguma coisa e elas lembram ah aqueles meninos vieram aqui e lembrarem dos movimentos e fazerem e verem que realmente isto é importante pra eles. (sic.).

Aluna 5: Às vezes a gente faz e nem conhece e agora eles vão fazer já conhecendo eles tão ali trabalhando e tão fazendo aquele serviço repetitivo dá uma dorzinha aqui 
uma dorzinha ali e daí eles vão e se alongam, eles tão executando mesmo que eles não lembram, antes eles não souberam disso. E quanto ao aprendizado, tirando por mim como base eu acho que aprendemos muito mais fácil porque o aluno ele tem muita dificuldade de prestar atenção quando é slide, quando é muito texto, na execução da atividade a gente aprende mais, a gente grava aquilo então num fica só temporariamente o conteúdo na nossa cabeça a gente vai lembrar depois de muito tempo também. (sic.).

Aluno 1: a nossa diretora, a (...), falou que gostou muito porque a nossa atividade laboral foi uma parte utilizado a música e ela gosta muito desse tipo de atividade e também teve outra funcionária que é a (...) ela também gosta muito de dançar então essa parte da música ela gostou bastante. (sic.).

Aluna 1: no nosso grupo particularmente, eles gostaram bastante até porque pela música que colocamos e eles pediram pra ter mais, eles perguntaram quais dias teriam, pra gente fazer um cronograma pra chamar eles, eles gostaram bastante. (sic.).

Os alunos avaliaram também a partir da interação e diálogo que tiveram, a percepção dos servidores e terceirizados que participaram da execução das atividades de ginástica laboral, perceberam uma aceitação muito boa, além da conscientização sobre a importância da ginástica laboral e uma boa qualidade de vida no trabalho. Foi perceptível também a participação dos servidores e o apelo dos mesmo para a contínua realização de atividades como aquelas.

As manifestações dos alunos demonstraram também a capacidade crítica de emitirem opiniões a partir de conceitos estudados durante as aulas. Para Correia (2011), as aulas de Educação Física no Ensino Médio devem possibilitar aos jovens, a partir dos conhecimentos sistematizados e aprofundados, a experiência de analisarem criticamente as diversas representações e significados atribuídos às diferentes manifestações corporais presentes em nossa sociedade. Sendo assim, a manifestação dos alunos a partir de debates articulados com base em conhecimentos organizados se aproxima do principal objetivo da escola, ou seja, que adquiram autonomia e tenham a possibilidade de serem agentes críticos e transformadores de sua realidade (MOREIRA; PEREIRA; LOPES, 2009).

\subsection{A EXPERIÊNCIA NO CAMPUS SÃo VICENTE}

No IFMT - Campus São Vicente, o conteúdo de Ginástica Laboral está contemplado no $3^{\circ}$ ano do curso técnico em agropecuária integrado ao ensino médio. Para tanto, foi ministrado e registrado - filmagem de todas as aulas - no ano de 2016.

A sequência pedagógica contemplou a ergonomia, ginástica laboral e técnicas alternativas, totalizando 8 aulas, tendo como objetivo das aulas a) conhecer os conceitos de ergonomia, ginástica laboral e técnicas alternativas; b) identificar, no dia a dia, posturas corporais corretas e incorretas; c) identificar, construir e aplicar um 'programa' de ginástica laboral na escola; d) experimentar técnicas de massagem e de relaxamento. 
Na primeira aula, os alunos conheceram o conceito de ergonomia e suas aplicações no cotidiano, além de observar e fotografar os colegas/alunos em situações do dia em dia para verificar se estavam utilizando uma postura corporal adequada ou não. As observações foram apresentadas na aula seguinte. Sobre a Ginástica Laboral, apresentamos os conceitos e aplicações da ginástica laboral em uma aula, tendo os alunos como atividade extraclasse a tarefa de entrevistar alguns servidores do campus para identificar suas necessidades e elaborar um programa de um dia para aplicação de ginástica laboral para estas pessoas (ou grupo de pessoas). Para finalizar a sequência de aulas, foram apresentados os conceitos de técnicas alternativas, sua utilização de algumas técnicas de massagem e relaxamento, finalizando com uma aula prática de massagem e relaxamento.

O conteúdo de Ginástica Laboral foi apresentado no decorrer de três aulas. A primeira aula seguiu a sequência de slides com as seguintes informações: conceito de GL, fazendo uma ligação ao que haviam aprendido sobre ergonomia, que se tratava de um tema que já havia sido objeto de questões do ENEM, e como se formariam em técnicos em agropecuária, poderiam se tornar chefes ou donos de alguma empresa. Sendo assim, ao conhecerem a importância da GL poderiam contratar um profissional para oferecê-la aos seus funcionários, melhorando a qualidade de vida e eficiência durante o trabalho. Apresentamos o conceito e sua operacionalização (sempre no local de trabalho e nunca fora do expediente), benefícios e a necessidade do diagnóstico; utilizamos os alunos como exemplos, além dos diversos setores do campus e suas necessidades específicas. Explicamos os três tipos de GL e seus exemplos: preventiva, terapêutica e de relaxamento. Como atividade para as duas aulas seguintes, propusemos a realização de uma GL compensatória com os funcionários da limpeza, refeitório e produção. Para isso, entregamos uma ficha de diagnóstico para entrevistarem os funcionários do campus. Discutimos a organização dos grupos, optando por realizar as entrevistas em duplas ou individualmente, para que, na aula seguinte, pudéssemos analisá-las e elaborar uma proposta de GL.

$\mathrm{Na}$ segunda aula tomamos como referência as fichas de diagnóstico preenchidas pelos alunos através de entrevistas com servidores do campus, sendo que uma das turmas realizou 9 entrevistas e a outra 12, algumas foram realizadas em duplas. Mesmo assim, muitos alunos não realizaram a entrevista ( 17 alunos de uma turma e 13 da outra).

A terceira aula foi destinada à aplicação de um programa de um dia de GL para os funcionários do campus, previamente combinado com cada setor. $\mathrm{O}$ intuito desta atividade não foi de instituir um programa de GL, até porque os alunos não cursam uma graduação em 
Educação Física, mas são estudantes do Ensino Médio capazes de conhecer e colocar em prática os conceitos apreendidos durante as aulas, constituindo-se numa oportunidade ímpar de socializarem seus conhecimentos, colocando-se em relação com outras pessoas, para além da sala de aula. Seguindo a ordem de aplicação das atividades de GL elaboradas, os dois primeiros grupos foram da turma 3B.

GL - Funcionários da limpeza (3B): encontramos os alunos na sala e logo nos dirigimos ao quiosque que fica ao lado do setor da limpeza, local combinado para realização da atividade. Participaram 8 pessoas, sendo 2 homens e 6 mulheres. Uma das alunas tomou a frente da atividade explicando quais as posturas corretas e incorretas empregadas na execução do serviço de limpeza, esclarecendo também o conceito de ergonomia, utilizando um balde e rodo para exemplificar as posturas, também observou que o rodo tinha um cabo longo, facilitando a manutenção da postura; explicou como carregar os baldes, distribuindo o peso entre os dois braços; demonstrou como carregar um material pesado, próximo ao corpo. A aluna ainda elucidou que fizeram o diagnóstico com alguns servidores e descobriram que as dores são predominantes na coluna e membros superiores, então propuseram alguns exercícios simples que poderiam ajudar a aliviar essas dores - os demais alunos a auxiliaram e, no momento da execução dos alongamentos, percebemos que alguns dos servidores não estavam conseguindo realizá-los, assim solicitamos para que os outros alunos os auxiliassem. A atividade durou 10 minutos, incluindo as explicações da aluna. A atividade foi finalizada com explanação dos alunos sobre os exercícios que poderiam melhorar o dia a dia dos funcionários, explicando também o objetivo da GL, ficando as atividades realizadas como "dicas" para tentarem realizar durante os momentos de pausa no trabalho.

GL - Pavilhão pedagógico (3B): combinamos previamente com os servidores (técnicos e professores) alocados no pavilhão pedagógico, que teríamos uma atividade de GL às $13 \mathrm{~h}$. Imediatamente após a realização da GL com os funcionários da limpeza, nos dirigimos até o hall do pavilhão pedagógico para que o segundo grupo realizasse a atividade, sendo que todos os alunos participaram das duas atividades. Inicialmente, explicamos aos servidores presentes (9) o que os alunos estavam estudando e o objetivo da atividade. Um dos alunos iniciou a GL explicando seu objetivo e os tipos, conduzindo, na sequência, os alongamentos, acompanhado por outros dois alunos. Um deles solicitou para que alguém do grupo auxiliasse os servidores que estavam fazendo o movimento incorretamente. Depois do alongamento, o grupo distribuiu bolinhas de borracha e um dos funcionários perguntou se fariam aula de reflexologia - este funcionário havia sido aluno do campus. $\mathrm{O}$ aluno que conduzia as atividades explicou que 
trabalharia com a bolinha porque eles passam muito tempo digitando ou escrevendo na lousa fez exercícios de apertar a bolinha com cada uma das mãos. Finalizaram a atividade com mais um alongamento para o pescoço, sugerindo que continuassem a praticar os exercícios todos os dias. Uma das professoras que participava das atividades sugeriu que o grupo imprimisse a sequência que propuseram num diagrama para fixar nos departamentos, porque assim assimilariam a sequência, lembrando de realizá-la todos os dias - a turma adorou a ideia e agradeceu. Retornamos à sala de aula para avaliarmos as atividades realizadas.

GL - Funcionários do refeitório (3A): Antes de iniciar a aula com o 3A, passamos no refeitório logo após o almoço e confirmamos com o chefe do setor a atividade de GL para às 13h30. No horário da aula com o 3A, reunimos os alunos na sala para seguirmos ao refeitório. Chegando no local da atividade, encontramos todos os funcionários trabalhando. Os convidamos para a GL, porém disseram que não poderiam sair, pois tinham tarefas a cumprir designadas pelo chefe imediato. Ninguém quis realizar nossa atividade! Ficamos frustrados, mas reunimos os alunos, explicamos a situação e eles sugeriram ir até o setor administrativo, porém tínhamos acabado de sair de lá com o 3B. Então, lembramos que havia outro setor administrativo, que ficava na outra parte do pavilhão pedagógico e ninguém de lá havia participado da atividade anterior.

Estes contratempos da prática docente exigem que o professor reflita não apenas antes ou depois da aula, mas o tempo todo, buscando ações rápidas para dirimir os problemas gerados. Para Franco (2012, p. 204):

[...] a ação crítica e reflexiva do sujeito sobre as circunstâncias presentes e, para essa ação, a pesquisa é inerentemente um processo cognitivo que subsidia a construção e mobilização dos saberes, construídos ou em construção.

Deste modo, a avaliação da prática docente é um processo inerente da pesquisa, mas não se restringe a ela, tampouco ao professor, pois "ao adentrar um processo contínuo de revisões da própria prática, acaba incorporando atitudes que o levam a constituir-se investigador no contexto da prática" (FRANCO, 2012, p. 202). No caso, os sujeitos envolvidos no processo, ou seja, os alunos, também entraram num processo de avaliação da situação-problema, refletindo e indicando possibilidades para sua resolução. A organização e o planejamento das aulas pelo professor também é primordial para a efetivação e cumprimento dos objetivos propostos, tornando-os “imprevistos” mais previsíveis e menos drásticos.

GL - Setor administrativo (3A): ao chegar ao setor, passamos de sala em sala convidando os servidores para participarem da GL. Alguns nos atenderam e foram participar 
da atividade, contando com 6 servidores, sendo 1 cadeirante. Expliquei o objetivo da GL preparada pelos alunos e um deles assumiu a atividade, explicando o conceito de GL, os tipos e objetivos. Outro aluno iniciou o alongamento e fez os exercícios, mas estava sem confiança e toda hora olhava como se pedisse ajuda. Os alunos fizeram o alongamento junto com ele. Tivemos um "vácuo" quando o alongamento foi concluído, pois o grupo do relaxamento não assumiu a atividade, então um dos alunos que filmava a atividade, entregou as bolinhas aos servidores e pediu para que as apertassem; neste momento, o diretor do campus apareceu e também participou da atividade; na sequência propuseram uma massagem nas costas, em duplas, com as bolinhas. Para finalizar, um dos alunos fez exercícios para o pescoço, movimentando-os. Explicamos a necessidade de realizarem pausas ativas durante o trabalho e agradecemos aos servidores participantes. Solicitamos aos alunos que retornassem à sala de aula para discutirmos a atividade.

Os conteúdos de ergonomia e ginástica laboral foram mencionados pelos alunos, destacando o seu interesse porque tiveram que conhecer primeiro os conceitos para depois ensinar/aplicar a outras pessoas. Os alunos manifestaram interesse em aprender porque puderam compartilhar seus conhecimentos, fazendo sentido para eles. É a aprendizagem para a vida, a relação entre os saberes e o mundo, os outros ou consigo mesmos, passando, então, a fazer sentido para eles (CHARLOT, 2000). Além disso, os alunos se sentiram valorizados, instigados a aprender para ensinar, formando sujeitos críticos e autônomos, capazes de agir no e sobre o mundo - são os objetivos da Educação Física na escola sendo atingidos. O diálogo do 3B destaca estes pontos:

\footnotetext{
Aluna 1: igual o que o Sidney disse, que a gente aprende aqui e vai para prática, acho que foi muito importante o que a gente fez com os funcionários, tipo, conseguir... a gente elaborar uma ginástica pra ir lá e fazer com eles. (sic.).
}

Aluna 2: é legal que você está ensinando a pessoa, né? (sic.).

Aluno 1: você começa a ter mais interesse porque você tem que explicar para os outros, você tem que saber o que você está fazendo. (sic.).

Aluna 1: a fazer o certo, né? (sic.).

Aluno 2: algo simples, ainda mais para eles que param no serviço (equipe da limpeza). (sic.).

Aluna 1: e eles também dão a opinião deles, depois uma lá falou "olha, vocês deviam ter feito tal e tal coisa, porque aqui a gente faz tal coisa". (sic.).

Houve exaltação no grupo ao lembrar da atividade de GL.

Aluno 2: você vê que é só no começo assim (faz gestos com a mão indicando que no começo não queriam fazer e depois se soltaram). (sic.). 
Outras manifestações corroboram a discussão anterior, em que os alunos citam conteúdos da ergonomia, ginástica laboral e técnicas alternativas, exemplificando situações aplicadas ou observadas em seu cotidiano.

Aluna 2: como as pessoas disseram aqui, como se comportar durante um jogo, como se comportar, como se sentar, postura (alunos se ajeitam na cadeira, sentando-se corretamente). A ginástica laboral foi boa também, eu usei em casa também, começou a doer minha perna e minha cabeça, eu fiz e melhorou de verdade (sic.).

Aluno 3: na empresa, lá no SEBRAE... eles fazem ginástica de 3 em 3 horas (sic.).

Aluno 4: ah, hoje eu tava utilizando a aula, o Igor desceu da van e tava com uma mochila pesada só de um lado, eu falei "Igor, coloca a outra alça", para ficar proporcional. Daí eu parei para pensar que eu não podia cobrar dele, porque como eu não tenho o trapézio de um lado, de qualquer forma ia ficar desproporcional para mim também, dependendo de qualquer forma que eu tiver, vai ficar torto o trem, por mais que já é torto porque eu já não tenho de um lado, eu acredito que vai ficar pesando desse aqui (e mostra o lado do ombro). Porque eu não tenho o trapézio de um lado, aí fica mais alto daqui (mostra o ombro), aí fica torto assim, e eu parei para observar por causa da aula da senhora. (sic.).

Aluno 5: eu achei mais massa tirar os servidores das cadeiras... eles ficam só sentados! Eles ficam lá tudo rindo "um, dois" (faz um alongamento para mostrar como os servidores faziam), pedindo para fazer desenho (com ilustração dos alongamentos), um monte de trem. (sic.).

Aluno 6: Igual, no caso de ergonomia, eu fiz um curso sobre isso, no SenaiEaD, e eu baixei um documento lá que falava a mesma coisa, e a partir dessa aula pude aplicar nas provas ali. É um conhecimento que você leva para vida inteira e você pode repassar para outras pessoas de uma maneira certa, não errada, não jogada (sic.).

Para Alcará e colaboradores (2009, p. 170), “o compartilhamento da informação e do conhecimento é essencial para a construção de novos conhecimentos, porém esse processo pode ser influenciado por diferentes fatores", como a natureza do conhecimento, a motivação e as oportunidades para compartilhar, que estão integrados à cultura organizacional do trabalho ou escola - no nosso caso, das próprias aulas de Educação Física. Para os autores, existe uma reciprocidade no compartilhamento de informações, em que as pessoas compartilham em troca de algo. Inicialmente, pode-se afirmar que os alunos compartilharam seus conhecimentos com outras pessoas em troca de nota para o componente curricular. Mas vamos além! Com base em Charlot (2000), há muito mais que motivação - externa (notas) - para executarem as atividades propostas, no caso a Ginástica Laboral com os funcionários do campus, houve uma mobilização (interno, do sujeito).

Os alunos relacionaram os conhecimentos aprendidos durante as aulas às suas vidas, ao que vivenciam, ao que observam ou aplicam em seu cotidiano. Para Charlot (2000) a relação com o saber é relação com o mundo, em um sentido geral, mas é, também, relação com esses mundos particulares (meios, espaços) nos quais o aluno vive e aprende. 
Para Kawashima (2018), os alunos ressignificam suas ações e pensamentos conforme as experiências vivenciadas durante as aulas de Educação Física. Sendo assim, quanto maior a diversificação dos conteúdos, promoção de discussões que os levem a refletir e criticar suas próprias ações enquanto agentes capazes de modificar uma realidade social, compreendendo o que e por que aprender os conhecimentos específicos da Educação Física, mais autonomia terão para escolher e criticar as diversas práticas corporais disponíveis em seu dia a dia ou na mídia.

\section{CONSIDERAÇÕES FINAIS}

O objetivo deste texto foi apresentar duas experiências com o conteúdo de ginástica, mais especificamente de ginástica laboral, em turmas de cursos técnicos integrados ao Ensino Médio do IFMT - campus Barra do Garças e campus São Vicente.

Nas duas experiências, foi desafiador envolver sujeitos externos à sala de aula para fazer parte do processo de ensino e aprendizagem dos alunos, bem como alça-los a condição de protagonistas na construção do conhecimento sobre a prática da ginástica laboral, possibilitando-os que conscientizem terceiros a partir do que aprenderam.

Na roda de conversa realizada em Barra do Garças, e descrita nos resultados, percebeuse a valorização dos alunos quanto ao fato de se tornarem centro no processo de ensino aprendizagem, na medida em que assumiram o papel de mediadores do conhecimento acerca da ginástica laboral.

Além disso, os alunos destacaram que assimilaram melhor o conteúdo e atribuíram esse fato à metodologia utilizada, pois as aulas se tornaram mais dinâmicas, produtivas e motivadoras já que precisavam, não só aprender o conteúdo como também transmiti-lo.

$\mathrm{Na}$ roda de conversa foi possível perceber também que a maioria dos alunos tinham pouco ou nenhum conhecimento prévio sobre ginástica laboral, e após a intervenção pedagógica supracitada, demonstraram em suas falas, que além de aprender passaram a valorizar e entender a sua importância.

O conteúdo de ginástica laboral foi mencionado pelos alunos, destacando que tiveram que conhecer primeiro os conceitos para depois ensinar/aplicar à outras pessoas. Isso ocorreu com outros conteúdos trabalhados durante a pesquisa também, em que os alunos manifestaram interesse em aprender porque puderam compartilhar seus conhecimentos, fazendo sentido para eles. Em um diálogo do 3B, os alunos demonstraram a importância que atribuíram à atividade e o quanto se sentiram motivados com o conteúdo por terem que explicá-lo e desenvolvê-lo para outras pessoas. 
Dessa forma, percebemos que em ambos os campi os alunos se sentiram valorizados e motivados com as sequências pedagógicas, avaliações e metodologias adotadas. Pudemos verificar por meio de suas falas que conseguimos atingi-los no que se refere aos conceitos e atitudes já que foram capazes de assimilar, transmitir e se conscientizar dos benefícios e importância da ginástica laboral.

É a aprendizagem para a vida, a relação entre os saberes e o mundo, os outros ou consigo mesmos, passando, então, a fazer sentido para os alunos (CHARLOT, 2000). Além disso, os alunos se sentiram valorizados, instigados a aprender para ensinar, formando sujeitos críticos e autônomos, capazes de agir no e sobre o mundo.

Certamente, se a estes alunos fossem oportunizadas apenas temáticas de suas escolhas, a ginástica laboral não seria citada. Isto ocorre porque, como mostraram os resultados, muitos alunos não tinham o conhecimento sobre a ginástica laboral, o que pode acontecer com outros conteúdos também, sendo que um dos objetivos das aulas foi de oportunizar aos alunos as mais diversas experiências das manifestações corporais e culturais. Dessa forma, este direcionamento do professor quanto aos conteúdos a serem ministrados nas aulas de educação física é de fundamental relevância para que o aluno tenha uma amplitude de vivências de práticas corporais na escola.

Além do conteúdo escolhido, a metodologia adotada possibilitou uma participação ativa do aluno, assumindo papel de protagonista do processo de ensino e aprendizagem ao se apropriar de conceitos, colocá-los em prática e compreender seus benefícios, se conscientizando de seus hábitos, deveres, valores e atitudes.

\section{REFERÊNCIAS}

ABRAHÃO, Julia; SZNELWAR, Laerte Idal , SILVINO, Alexandre . Introdução a ergonomia: da prática a teoria. São Paulo, SP: Blucher, 2009.

ALCARÁ, Adriana Rosecler. Fatores que influenciam o compartilhamento da informação e do conhecimento. Perspectivas em ciência da informação. Belo Horizonte, UFMG, vol. 14, $\mathrm{n}^{\mathrm{o}} 1$, jan./abr. 2009, p. 170 - 191.

ALMEIDA, Rogério, Marques e colaboradores. A educação física em três campi do IFMT: do saber instituído à prática pedagógica. Revista da Faculdade de Educação. Cáceres, MT, v. 20, n. 2, jul./dez., 2013, p. 35-54.

BRASIL. Lei de Diretrizes e Bases da Educação Nacional. (LEI n 9.393/96). Brasília, 1996. 
BRASIL. Base nacional comum curricular. Brasília: MEC, 2017. Disponível em: http://basenacionalcomum.mec.gov.br/images/BNCC_EI_EF_110518_versaofinal_site.pdf Acesso em: 03 de janeiro de 2020.

CARVALHO, Amarilis Oliveira; DITOMASO, Aline. Ginástica no ensino médio. In: DARIDO, Suraya Cristina (org.). Educação física no ensino médio: diagnóstico, princípios e práticas. Ijuí: Ed. Unijuí, 2017, p. 407-423.

CHARLOT, Bernard. Da relação com o saber: elementos para uma teoria. Porto Alegre, RS: Artes Médicas Sul, 2000.

CORREIA, Walter Roberto. Educação Física no ensino médio: questões impertinentes. 2. ed. Várzea Paulista, SP: Fontoura, 2011.

DARIDO, Suraya Cristina; RANGEL, Irene Conceição Andrade. Educação Física na escola: implicações para a prática pedagógica. Rio de Janeiro: Guanabara Koogan, 2005.

FENSTERSEIFER, Paulo Evaldo; GONZÁLEZ, Fernando Jaime. Desafios da legitimação da educação física na escola republicana. In: Horizontes, Dourados, MS, n. 2, v1, jul./ dez., 2013.

GONZÁLEZ, Fernando Jaime; FENSTERSEIFER, Paulo Evaldo. Entre o "não mais" e o "ainda não": pensando saídas do não-lugar da EF escolar I. In: Cadernos de Formação RBCE. Campinas, SP: CBCE e Autores Associados, v.1, n.1, 2009, p. 09 -24.

KAWASHIMA, Larissa Beraldo. Sentidos e significados da educação física para os alunos do IFMT - campus São Vicente: a pesquisa-ação como forma de construção coletiva de conhecimentos. 723f. Tese (Doutorado em Educação) Programa de Pós-Graduação em Educação, Universidade Federal do Mato Grosso, Cuiabá, MT, 2018.

LIMA, Deise Guadalupe de. Ginástica laboral: metodologia de implantação de programas com abordagem ergonômica. Jundiaí, SP: Fontoura, 2004.

LÜDKE, Menga; ANDRÉ, Marli Eliza Dalmazo Afonso de. Pesquisa qualitativa em educação: abordagens qualitativas. São Paulo: EPU, 1986.

MELO, Marcia Cristina Henares de; CRUZ, Gilmar de Carvalho. Roda de conversa: uma proposta metodológica para a construção de um espaço de diálogo no ensino médio. Imagens da Educação. Ponta Grossa, PR, v. 4, n. 2, maio, 2014 p. 31-39.

MOREIRA, Evando Carlos; PEREIRA, Raquel Stoilov; LOPES, Tomires Campos. Desafios e propostas para a educação física no ensino médio. In: MOREIRA, Evando Carlos; NISTAPICCOLO, Vilma Leni. (Orgs.). O quê e como ensinar educação física na escola. Jundiaí, SP: Fontoura, 2009, p. $177-197$.

NISTA-PICCOLO, Vilma Lení; MOREIRA, Wagner Wey. Esporte para a vida no ensino médio. São Paulo: Telos, 2012.

NOGUEIRA, Valdirene Aline. FARIAS, Uirá de Siqueira. Educação Física na Educação Básica: cenas de um cotidiano escolar repletos de práticas pedagógicas inovadoras. In: NOGUEIRA, Valdirene Aline. FARIAS, Uirá de Siqueira. Práticas pedagógicas inovadoras 
nas aulas de educação física escolar: indícios de mudanças 2. 1. ed. Curitiba: PR: CVR, 2017, p. 15-22.

RANGEL, Irene Conceição Andrade. Educação física e educação física na escola: uma história de glórias, medalhas e... exclusões. In: MOREIRA, Evando Carlos (Org.). Educação física escolar: desafios e propostas 1. 2. ed. Jundiaí, SP: Fontoura, 2009, p. 213-228.

SORIANO, Raúl Rojas. Manual de pesquisa social. Petropólis-RJ: Vozes, 2004.

SOUZA FILHO, Moyses de. Novas territorialidades pedagógicas para a educação física no ensino médio integrado: uma perspectiva pós-crítica. 2014. 234f. Tese (Doutorado em Educação) Programa de Pós-Graduação em Educação, Universidade Federal do Rio Grande do Norte, Natal, RN, 2014.

VAGO, Tarcísio Mauro Vago. Pensar a educação física na escola: para um a formação cultural da infância e da juventude. In: Cadernos de Formação RBCE. Campinas, SP: CBCE e Autores Associados, v.1, n.1, 2009, p. 25-42.

Recebido em: 24 de fevereiro de 2020 . Aprovado em: 08 de abril de 2020. 